\title{
Osteoblast cell response to titanium dental implant surfaces treated withdifferent chemical agents
}

Roland Masa ${ }^{\star}$, István Pelsőczi-Kovács², Zoltán Aigner ${ }^{3}$, Albert Oszkó ${ }^{4}$, Kinga Turzó ${ }^{1}$, Krisztina Ungvári ${ }^{1}$ 'Department of Oral Biology and Experimental Dental Research, Faculty of Dentistry, University of Szeged, H-6720 Szeged, Hungary

${ }^{2}$ Department of Prosthodontics, Faculty of Dentistry, University of Szeged, H-6720 Szeged, Hungary

${ }^{3}$ Department of Pharmaceutical Technology, Faculty of Pharmacy, University of Szeged, H-6720, Szeged, Hungary

${ }^{4}$ Department of Physical Chemistry and Materials Science, Faculty of Science and Informatics, University of Szeged, H-6720 Szeged, Hungary

\section{Abstract}

Relatively high survival rates of dental implants encourage clinicians to use this type of oral rehabilitation frequently in their
daily practice. However, implant failures are increasing parallel with the number of implant placements. Bacterial colonization is one of the main causes of periimplant inflammation. In the therapy of both periimplant mucositis and periimplantitis mechanical debridement and chemical decontamination are fundamental steps.

- In order to be up to date in the fight against bacteria, various types of antibacterial solutions should be used during pocket irrigation. However, they should undergo through different in vitro and in vivo tests before daily use In this study the response of primary esteoblast cells to chemically treated titanium surfaces was osteoblast cells to chemically treated titanium surfaces was visualization fluorescent staining were carried out.

\section{Background and Aim}

In case of periimplant infections, the main goals of treatment are to decontaminate the dental implant surface, in order to reduce the bacterial load and to facilitate reintegration. ${ }^{1}$ Various chemical agents have been proposed for surface decontamination in the therapy of periimplantitis. ${ }^{2}$ However, these antibacterial agents could alter the surface properties of the implant material and also the cell (osteoblast) response.

Our aim was to evaluate the interaction of titanium dental implant surface with three different antibacterial solutions: chlorhexidine, povidone-iodine and chlorine dioxide. Our null hypothesis was that residues of these agents do not modify either the implant surface or the osteoblast response.

\section{Methods and Materials}

Commercially pure (CP4) sandblasted, acid-etched titanium sample discs (Denti® System Ltd., Hungary) $1.5 \mathrm{~mm}$ thick and $9 \mathrm{~mm}$ in diameter, rinsed with ultrapure water, were used as control surfaces. Three different chemical agents were investigated: chlorhexidine digluconate (CHX, Curasept ADS 220, 0.2\%, Switzerland), povidoneiodine ( PVPI, Betadine, $10 \%$, Switzerland) and chlorine dioxide solution $\left(\mathrm{ClO}_{2}\right.$, Solumium, $0.12 \%$, Hungary). Titanium sample discs were treated for 5 minutes in each case.

Wettability studies were performed by an OCA 20 (Dataphysics, Filderstadt, Germany) contact angle measuring device with water and diiodomethane drops. Surface free energy (SFE) was determined according to Owen-Wendt-Rabel-Kaelble (OWRK) method. The chemical compositions of the $\mathrm{Ti}$ discs were studied by X-ray photoelectron spectroscopy (XPS) In vitro attachment (24h) and pholiferation (72h) of primary osteoblast cells were investigated and dimethylthiazol- diphenyltetrazolium bromide (MTT) and fluorescence microscopy.

\section{Results}

Contact angle measurements revealed significant differences in SFE of the treated discs compared to the control Ti surface. Povidoneiodine treated samples had the lowest contact angles and the highest SFE. Chlorhexidine $(\mathrm{CHX})$ - and chlorine dioxide $\left(\mathrm{ClO}_{2}\right)$ - treated discs showed significantly higher contact angle values compared to control Ti samples.

XPS confirmed the constant presence of typical surface elements ( $\mathrm{Ti}$, $\mathrm{O}, \mathrm{C}, \mathrm{N}$ ) on each surface, while chlorine was detected only in the $\mathrm{ClO}_{2}$ group.

MTT test proved the viability of primary osteoblast cells after chemical agent treatment. In spite of the significant difference in surface free energy, and the chlorine presence in the $\mathrm{ClO}_{2}$ group, MTT assay indicated similar osteoblast cell attachment $(24 \mathrm{~h})$ in the three study groups and the control groups (plate and Ti). After $72 \mathrm{~h}$, a significant increase was observed in cell numbers (high proliferation rate) in all of the investigated groups compared to cell numbers after $24 \mathrm{~h}$, no the investigated groups compared to cell numbers after 24h, no significant difference was found beetwen the groups. Fluorescent images confirmed these results.

\section{Acknowledgments}

The work was supported by the grant GINOP-2.3.2-15-2016-00011 to a consortium led by the University of Szeged, Szeged, Hungary.

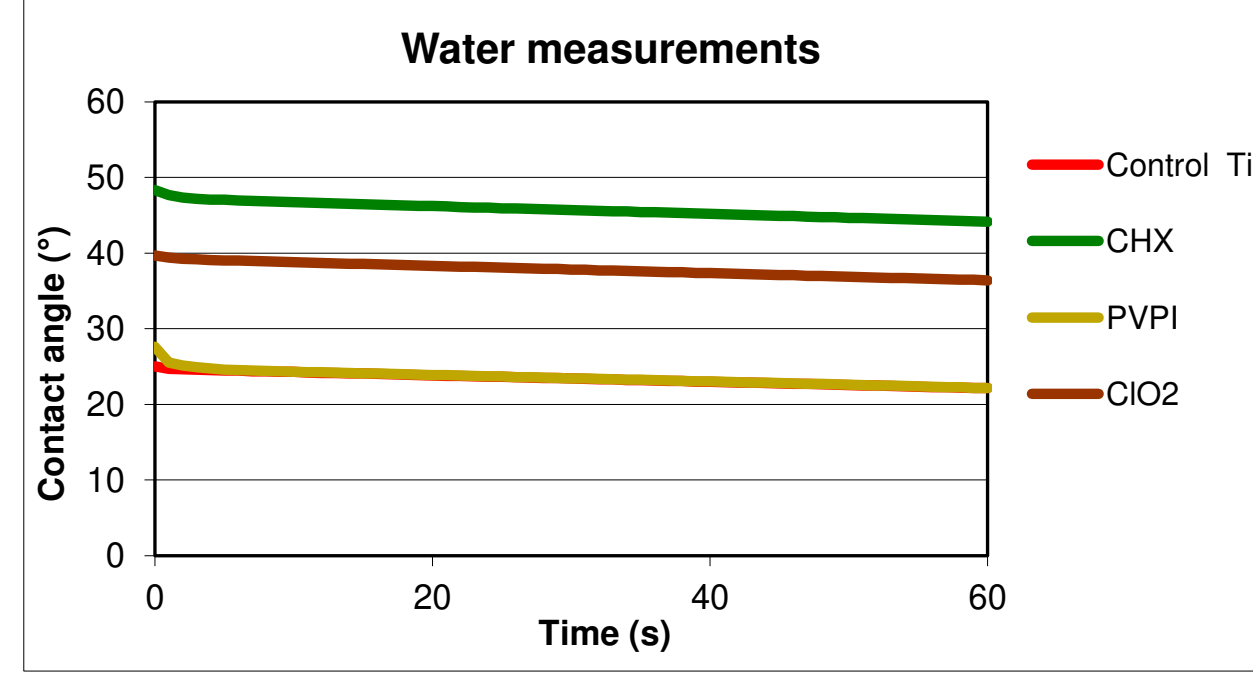

Figure 1. Contact angle values of the different surfaces are presented, using water drops.

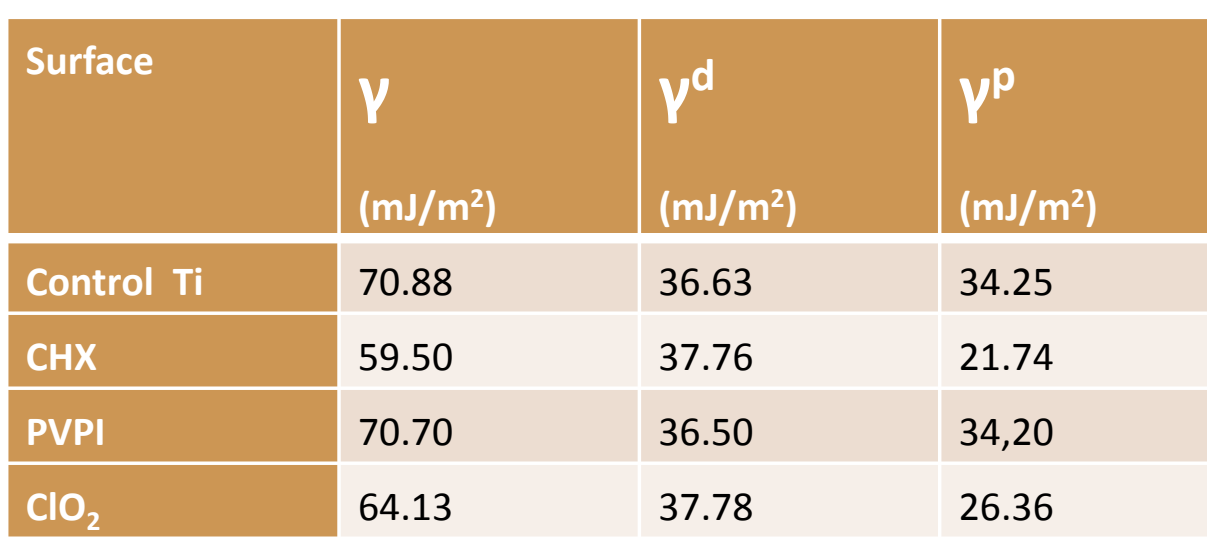

Table 1. The SFE $(\gamma)$ and its disperse $\left(\gamma^{d}\right)$ and polar $\left(\psi^{\mathrm{p}}\right)$ components of the discs, calculated with the Owen-Wendt-Rabel-Kaelble (OWRK) method. Data presented as mean

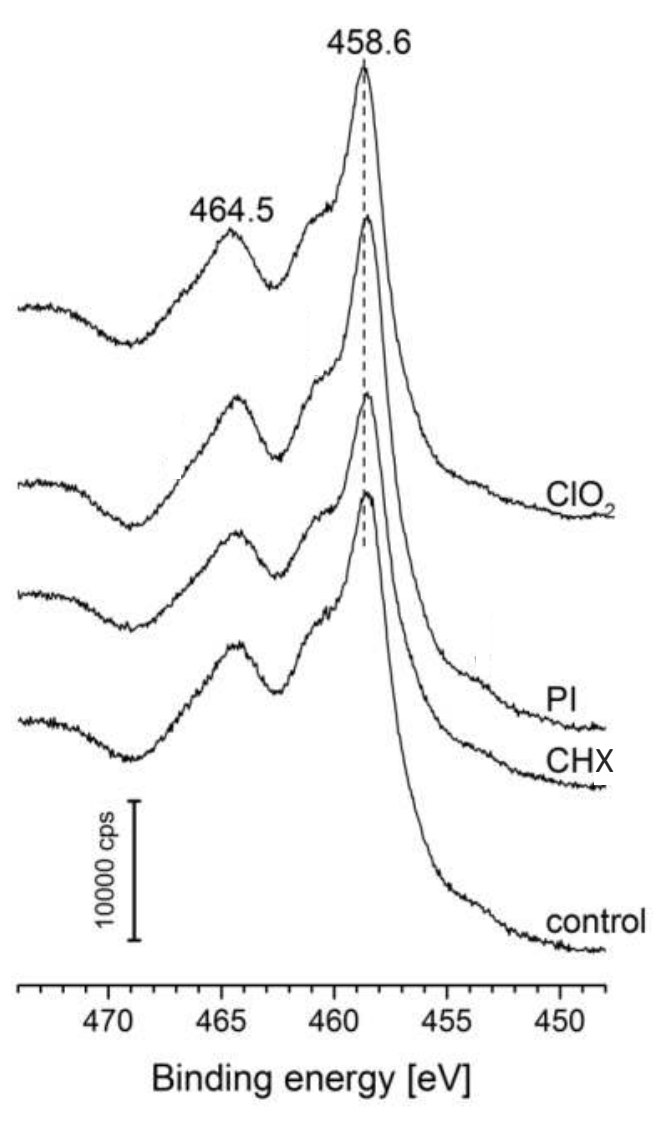

Figure 2. Ti $2 p$ signals in XPS spectra of Control Ti, $\mathrm{CHX}, \mathrm{PVPI}$ and $\mathrm{ClO}_{2}$ treated Ti discs, confirming

the presence of $\mathrm{TiO}_{2}$ on all surfaces.

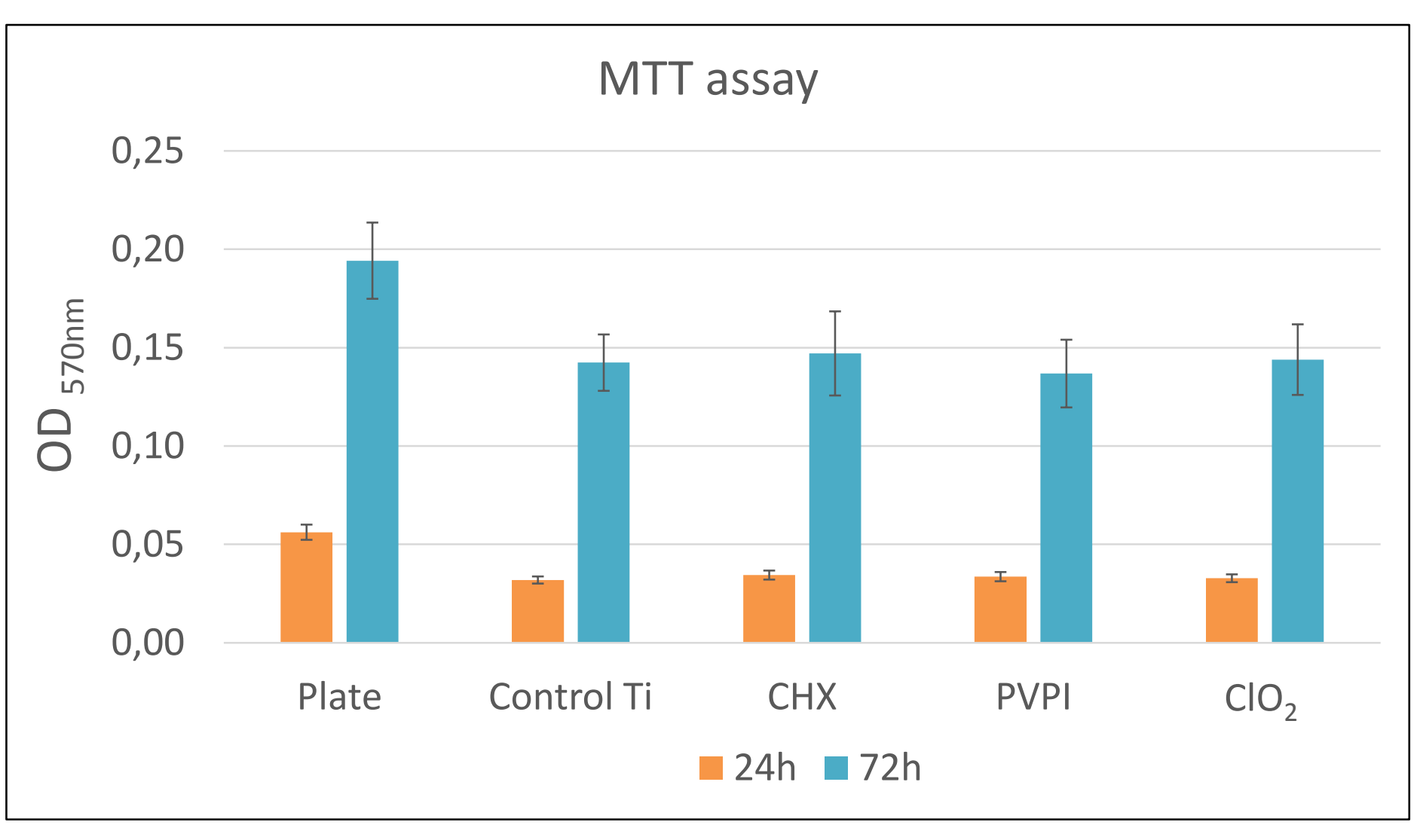

Figure 3. 24 and $72 \mathrm{~h} \mathrm{OD}_{570}$ values of osteoblast cells incubated with MTT on the control (plate and uncovered Ti) and chemical agent treated discs. Data are presented as mean \pm SD.

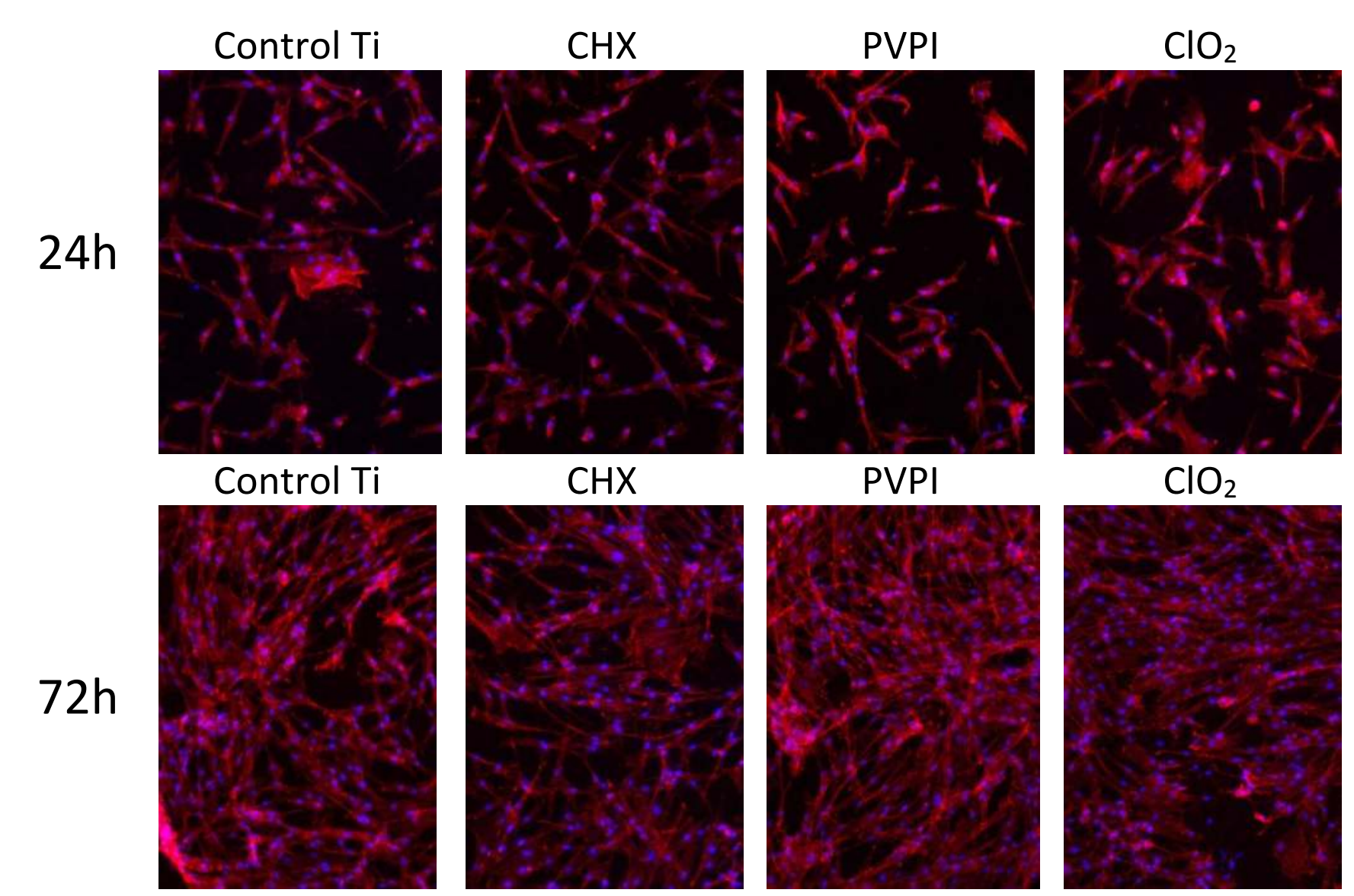

Figure 4. Fluorescent images of primary osteoblast cells attachment and proliferation after 24 and $72 \mathrm{~h}$.

\section{Conclusions}

- In spite of the different wettabilities, primary osteoblast cells showed similar response and high viability on each of the surfaces. Therefore, it seems no far-fetched to assume that none of the irrigating agents would have a negative influence on osseointegration. In conclusion, we suggest the use of PVPI and high purity $\mathrm{ClO}_{2}$-solution beside the gold standard $\mathrm{CHX}$ as implant surface decontaminating agents, in order to reach broader antibacterial efficiency.

\section{References}

1. Renvert et al. Non-surgical treatment of peri-implant mucositis and peri-implantitis: a literature review. J Clin Periodontol, 2008

2. Valderrama et al. Detoxification of implant surfaces affected by periimplant disease: an overview of surgical methods. Int J Dent, 2013.

3. Ungvári et al. Effects on titanium implant surfaces of chemical agents used for the treatment of peri-implantitis. Journal of Biomedical Materials Res. B, App. Biomat. 2010 